\title{
Sugar Replacement Applications in Cakes: Effect on Cake Texture and Sweetness
}

\author{
Ceyda Dadali \\ Ege University, Engineering Faculty, Food Engineering Department, \\ 35100, Bornova, Izmir, Turkey \\ E-mail: ceyda.dadali@gmail.com \\ Yesim Elmaci (Corresponding author) \\ Ege University, Engineering Faculty, Food Engineering Department, \\ 35100, Bornova, Izmir, Turkey \\ E-mail: yesim.elmaci@ege.edu.tr
}

\begin{abstract}
Cake is a bakery product with high sugar content which is appreciated by the consumer with its flavour and soft texture. Studies on sugar content reduction increased due to foods with high sugar content causing dental problems, cardiovascular diseases, obesity and type 2 diabetes. Sugar used in cakes affects colour, flavour and texture of the cake. $15-20 \%$ sugar reduction can be achieved without major changes in cake formulation. However, to reduce sugar more than $20 \%$, it is determined that a mixture of sweeteners and sweeteners in combination with bulking agents should be used in order to obtain the colour, flavour and texture of the sugar-reduced cake similar to the cake with high sugar content. In sugar replacement studies in cakes natural and artificial sweeteners as sweetener, sugar alcohols as sweetener and polymers such as polydextrose, inulin, oligofructose, hydrocolloids and some fiber sources as bulking agent are used. In this review, it is aimed to give information about sugar replacement applications in cakes and effect of these applications on cake characteristics.
\end{abstract}

Keywords: cake, sucrose, sucrose replacement, sugar reduction.

DOI: $10.7176 / \mathrm{JSTR} / 5-8-03$

\section{Keklerde Şeker İkame Uygulamaları: Kek Yapısına ve Tatlılığına Etkisi}

Özet

Kek, lezzeti ve yumuşak dokusuyla tüketici tarafından beğenilen yüksek şeker içeriğine sahip bir firın ürünüdür. Yüksek şeker içeriğine sahip gıdaların dental sorunlara, kardiyovasküler hastalıklara, obeziteye, tip 2 diyabete sebep olması nedeniyle şeker içeriğini azaltmasına yönelik çalışmalar hız kazanmaktadır. Kekte kullanılan şeker kekin rengi, lezzeti ve dokusuna etki etmektedir. Şeker içeriğinin \%15-20 azaltılması kek formülasyonunda büyük değişikler yapılmadan sağlanabilmektedir. Ancak \%20'nin üzerinde şeker azaltılmaya çalışıldığında ise şeker içeriği azaltılmış kekin renk, lezzet ve doku özelliklerinin şeker içeriği yüksek olan keke benzer olması için tatlandırıcıların genellikle karışım halinde ve hacim vericilerle beraber kullanılması gerektiği belirlenmiştir. Keklerde şeker ikamesi yapılan çalışmalarda tatlandırıcı olarak doğal ve yapay tatlandırıcılar, tatlandırıcı ve hacim verici olarak şeker alkolleri, hacim verici olarak polidekstroz, inülin, oligofruktoz gibi polimerler, hidrokolloidler ve bazı lif kaynakları kullanılmaktadır. Bu derlemede keklerde yapılan şeker ikame uygulamaları ve bu uygulamaların kek karakteristiklerine etkisi hakkında bilgi verilmesi amaçlanmıştır.

\section{Giriş}

Kek, tüketici tarafından yüksek kabulü olan, pazarı her yıl dünya çapında \%1.5 artan popüler atıştırmalık ürünlerden biridir (Wilderjans et al., 2013; Gao et al., 2016). Kek bileşimi genellikle şeker, yağ, buğday 
unu, yumurta ve sütten oluşmaktadır. Formülasyonuna bağlı olarak kek yaklaşık \%10-30 oranında şeker, \%20-50 oranında yağ içermektedir (Akesowan, 2009). Yüksek şeker ve yă̆ içeriği sebebiyle yüksek kalori değerine sahip olan kekin ana bileşenlerinden biri olan sakkarozun kekte birçok fonksiyonu mevcuttur. Sakkaroz keklerde tatlılığı sağlamakta, Maillard reaksiyonlarıyla pişmiş kek renginin oluşmasını sağlamakta, kek hamurunun viskozitesini artırıp, daha çok hava tutulmasını sağlamakta ve nişasta jelatinizasyon sıcaklığını artırmaktadır (Beesley, 1995; Baeva et al., 2003; Ronda et al., 2005; Kocer et al., 2007). Sakkarozun kekteki bu fonksiyonlarının yanında günlük şeker tüketiminin fazla olması, fazla enerji alımına sebep olmakta (Bailey et al., 2018), diyet kalitesini düşürmekte (Louie and Tapsel, 2015) ve dental sorunlara, kardiyovasküler hastalıklara, obeziteye, tip 2 diyabete ve kansere sebep olmaktadır (Rößle et al., 2011). Son yıllarda şeker tüketimine bağlı olarak sağlık problemlerinin artması sebebiyle tüketiciler diyetle aldıkları şeker miktarını azaltma eğilimi göstermektedir. Bu sebeple tüketicinin de talebini karşılamak amacıyla yüksek şeker içeriğiyle bilinen kek yerine düşük kalori ve şeker içeriğine sahip kekler gıda sanayinin odağındadır. Sakkarozun kekte tatlılığı sağlamasının yanında kompleks yapısal fonksiyonları sebebiyle düşük şeker içeriğine sahip aynı zamanda da tüketicinin beğenisini kazanacak keklerin üretilmesini zorlaştırmaktadır. $\mathrm{Bu}$ çalışmada keklerdeki sakkaroz miktarını azaltmak amacıyla sakkaroz kullanılan keklere benzer yapıda kek elde edilmesi amacıyla kullanılan şeker ikame uygulamalarının derlenmesi amaçlanmıştır.

\section{Sakkarozun Kekteki Fonksiyonları}

Kekin ana bileşenlerinden olan sakkarozun tatlılığı sağlamanın yanı sıra kekin yapısında teknolojik olarak birçok fonksiyonu mevcuttur. Sakkaroz kek yapısında girdiği reaksiyonlar sebebiyle kekin rengine, lezzetine ve dokusuna etki etmektedir.

Kek hamurunun karıştırılması sırasında 1-2 $\mu$ m'lik yăg kristalleri kek hamurunun hava tutma kapasitesinde en etkin boyutlardır. Kek hamurundaki sakkaroz yăg kristal kümelerinin kırılmasına yardımcı olup, daha küçük boyuttaki kristallerde daha fazla hava tutulmasına yardımcı olmaktadır (Wilderjans et al., 2013).

Sakkaroz kekin pişirilmesi sırasında 1sı ile indüklenen reaksiyonlara girerek pişmiş kek renginin oluşmasını sağlamaktadır. Sakkaroz pişirme sıcaklığında monomerlerine parçalanarak Maillard reaksiyonlarında yer almaktadır. Maillard reaksiyonları ile kekte önemli lezzet bileşikleri ve kararma ürünleri oluşmaktadır. Ayrıca karamelizasyon reaksiyonlarıyla da kahverengimsi-sarımsı yüzey renginin oluşumuna, karamelimsi lezzet oluşumuna katkı sağlamaktadır (Davis et al., 1995; Varzakas and Ozer, 2012). Kek formülasyonundaki sakkaroz viskozitenin artmasını sağlamakta ve daha fazla hava kabarcığının kek hamuru içinde tutulmasına, yayılmasına yardımcı olmaktadır. Daha fazla hava kabarcığ bulunduran kek hamurları pişirme sonrasında daha hacimli yapıda olmaktadır (Paton et al., 1981). Sakkaroz ayrıca nişasta jelatinasyonunu, protein denatürasyonunu ve camsı geçiş sıcaklığını etkilemektedir (Davis, 1995). Kek hamurunda gluten molekülleri su tutmakta ve nişasta molekülleri içinde çapraz bağlı gluten ağı oluşturmaktadır. Pişirme sırasında sıcaklığın artmasıyla buğday proteinleri denatüre olup su tutma kapasitelerini kaybetmektedir ve su nişasta moleküllerine geçerek nişastanın şişmesine sebep olmaktadır. Nişasta jelatinizasyon sıcaklığına ulaştığında ise nişasta granülleri parçalanmakta, kristalliğini kaybetmekte ve amiloz, amilopektin salınımıyla viskozite artmaktadır (Pomeranz et al., 1984). Kek hamurunda yer alan sakkaroz higroskopik olup su için nişasta ile yarışmakta ve nişasta molekülleri için olan su molekülünü azaltıp su aktivitesini düşürmektedir (Perego et al., 2007). $\mathrm{Bu}$ durumda nişasta jelatinizasyon sıcaklığını yaklaşık $20^{\circ} \mathrm{C}$ artırmaktadır. Jelatinizasyon sıcaklığının artmasıyla kek içinde daha çok karbondioksit ve su buharı tutulmakta, kekin mikroyapısı, porozitesi iyileşmekte ve hacmi artmaktadır (Kim and Setser,1992; Kocer et al., 2007).

\section{Keklerde Kullanılan Sakkaroz İkameleri}

Keklerde yapılan şeker azaltma çalışmalarında sakkaroz yerine şeker alkolleri, doğal tatlandırıcılar ve yapay tatlandırıcıların kullanıldığı saptanmıştır (Tablo 1). Genel olarak kek tipi ürünlerde \%15-20 arasında şeker azaltılması kek formülasyonunda büyük değişikler yapılmadan sağlanabilmektedir. Ancak \%20’nin üzerine çıkıldığında kekin hem tatlılığının hem de dokusal özelliklerinin sağlanmasında tatlandırıcıların genellikle karışım halinde ve hacim vericilerle beraber kullanılması gerektiği vurgulanmıştır (Nip, 2006). Keklerin dokusal özelliklerinin sakkaroz kullanılan keklerle benzer özellikte olması amaciyla polidekstroz, oligofruktoz, inülin gibi polimerlerin, hidrokolloidlerin (gam arabik, ksantan, guar gam, karragenan, karboksimetilselüloz) ve bazı lif kaynaklarının kullanıldığı belirlenmiştir. Polidekstroz hacim verici olup keklerde şeker ve yağ ikamesi olarak kullanılan çapraz bağlı, kısmi olarak metabolize olan glukoz polimeri olup sakkarozun tatlık ve kristalizasyon dışındaki kekteki 
fonksiyonlarını sağlamaktadır. Kalori değeri çok düşük (1 kcal/g) olan polidekstroz serum glikoz seviyesini yükseltmemesi, insülin ihtiyacı oluşturmamasıyla diyabet hastaları için uygundur (Roberfroid and Slavin, 2000). Polidekstroz tatlılık sağlamaması sebebiyle genelde tatlandırıcılarla birlikte kullanılmaktadır (Ronda et al., 2005; Martínez-Cervera et al., 2012a; Psimouli and Oreopoulou, 2012; Schirmer et al., 2012; Zahn et al., 2012;). Ancak keklerin dokusal özelliklerinin değerlendirildiği şeker ikamesi olarak sadece polidekstrozun kullanıldığı çalışmalar da mevcuttur. Hicsasmaz et al. (2003) kek formülasyonlarında $\% 25, \% 50, \% 75$ ve $\% 100$ oranında polidekstroz ile sakkarozu ikame ettiğ $i$ çalışmada \%100 oranında sakkaroz ikamesi yapılan kek hamurlarının hava kabarcığı büyüklük dağılımının kontrol kekiyle benzer özellikte olduğunu gözlemlemiştir. Sakkaroz ikame oranı \%50'nin üzerine çıktığında kek hamurunun akma süresinde önemli azalma belirlenmiştir. Kontrol kekiyle benzer kek hamuru karakteristikleri, porozite, gözenek büyüklüğü ve şekil dağılımı \%25 sakkaroz ikamesi ile sağlanmış olup kekin kalorisinin \%18.75 azaltılması sağlanmıştır. Ancak kekin kabarması, kek yüksekliği, yarık tipi, hücre yapısı ise şeker ikame oranının artışıyla beraber azalmakta, küçük küresel hücre yapısı ise artmaktadır. Polidekstrozla yapılan sakkaroz ikamesi ayrıca kek kabuğunda kırmızılıkta artış, parlaklıkta ise azalışla sonuçlanmaktadır.

Yüksek hacimli keklerde polidekstrozun sakkaroz ikamesi olarak \%20, \%40, \%60, \%80 ve $\% 100$ oranında kullanıldığı bir çalışmada polidekstroz kullanımının kek hamurunun stabilitesini azalttığ1, akma süresini düşürdüğü, ortalama hava kabarcığı büyüklüğünü azalttığ1 ve homojenliği artırdığ1 belirlenmiştir. Kekte ise polidekstrozun sakkaroz ikamesi olarak kullanımı ortalama gözenek büyüklüğünü ve homojenliğini artırmaktadır. Sakkaroz ve yağ ikamesi olarak eşzamanlı kullanımı optimize edildiğinde polidekstrozun \%22 sakkaroz ikamesi ve \%25 yağ ikamesi olarak kullanılabileceği ve \%22 oranında kalori değerinin azaltılmasını sağladığı belirlenmiştir (Kocer et al. 2007).

İnülin ve oligofruktoz şeker azaltma çalışmalarında keklerin doku özelliklerinin sakkaroz kullanılan keklere benzer olması amacıyla kullanılan fruktan olarak adlandırılan polimerik karbonhidratlardır. İnülin, fruktoz oligomer ve polimeri içeren genellikle glukoz molekülüyle sonlanan $\beta$ (2-1) bağlı, polimerizasyon derecesi ortalama 10 olan polidispers fruktandır (Niness, 1999). Oligofruktozun polimerizasyon derecesi 2-8 aralığında olup inülinin kısmı hidroliziyle elde edilmektedir (Hempel et al., 2007). Fruktanlar kısmi olarak metabolize olmaktadır ve $1.5 \mathrm{kcal} / \mathrm{g}$ enerji sağlamaktadır. İnce bağırsakta sindireme uğrayamamakta, ancak kalın bağırsakta mikrobiyota tarafından kısmi olarak metabolize edilerek kısa zincirli yağ asitleri, laktik asit ve gaz oluşmaktadır (de Leenheer, 1996). Keklerde kullanılan sakkarozu azaltmak amacıyla genellikle tatlandırıcılarla birlikte fruktanlar kullanılmaktadır (Ronda et al., 2005; Psimouli and Oreopoulou, 2012; Zahn et al., 2012; Gao et al., 2016). Rodríguez-García et al. (2014) ise sakkarozu $\% 20, \% 30, \% 40$ ve $\% 50$ seviyesinde inülin ile ikame ettiği çalışmasında inülin kullanılan kek hamurunun kontrol kek hamuruna göre görünür viskozitesinin düşük olduğu belirlenmiştir. Sakkaroz yerine inülin kullanılan pişmiş keklerde daha küçük ve az hücre oluşumu gözlenmiş ve kek yüksekliğinin kontrol kekine göre daha az olduğu belirlenmiştir. İnülin içeren keklerde sertlik ve iç yapışkanlık düşük, esneklik ise yüksektir. Kekte \%30 oranında inülin ile şeker ikamesi yapılmasının duyusal olarak genel kabulü etkilemediği belirlenmiştir.

\section{1 Şeker Alkolleri}

Poliol olarak da adlandırılan şeker alkolleri sakkarozun sağladığı hacim, dokusal özellikler ve tatlılığı sağlaması sebebiyle sakkoroz yerine firın ürünlerde tercih edilmektedir. Keklerde şeker ikamesi olarak şeker alkollerinin kullanıldığı çalışmalarda eritritol, izomalt, ksilitol, laktitol, maltitol, mannitol ve sorbitolün kullanıldı̆̆ 1 tespit edilmiştir.

Eritritol dört karbonlu şeker alkolü olup sakkarozun tatlılığının \%60-80'ini eritritol sağlayabilmektedir (Goossens and Roeper, 1994). Doğal olarak meyvelerde ve fermente ürünlerde bulunan (Lin et al., 2003) eritritol ticari olarak fermentasyon yoluyla üretilmektedir (Lin et al., 2001). Eritritolün sağladığ enerji $0.5 \mathrm{kcal} / \mathrm{g}$ 'dan daha az olup kandaki glukoz ve insülin seviyesini etkilememektedir (Tetzloff et al., 1996). Eritrol suda orta düzeyde çözünmektedir ve yüksek sıcaklıklara da dayanıklıdır (de Cock, 2012). Lin et al., (2003) kekte sakkarozun \%25, \%50, \%75 ve \%100 oranında eritritol ile ikame edildiğinde eritritol kullanılan keklerin kabuk ve iç renklerinin daha açık olduğunu ve keklerin daha az tatlı olduğunu belirlemiştir. Sakkaroz kullanılan kekler ile eritritol kullanılan kekler kıyaslandığında kek hamurlarının spesifik yoğunlukları, keklerin hacim ve nem içerikleri arasında fark olmadığ

Izomalt $\alpha$-D-glukopiranosil- $\alpha$-(1-6)-sorbitol ve $\alpha$-D-glukopiranosil- $\alpha$-(1-6)-mannitolun eşmolar karışımıdır (Bornet, 1994). İzomaltulozun katalitik hidrojenasyonuyla üretilen izomaltın tatlılı̆̆ sakkarozun \%50'si kadardır (Zumbé et al., 2001). İzomalt kokusuz olup, düşük higroskopik özelliğe

27 I $P$ a g e

www.iiste.org 
sahiptir. A ğızda soğutucu etki yaratmakta ve sağladığı tatlılık tat sonrası izlenim yaratmamaktadır. Ayrıca izomalt Maillard reaksiyonlarına girmemektedir (Deis and Kearsley, 2012).

Tablo 1. Keklerde şeker azaltmak amacıyla yapılan çalışmalarda sakkaroz yerine kullanılan ikameler

\begin{tabular}{|c|c|c|}
\hline Sakkaroz yerine kullanılanlar & Sakkaroz yerine kullanılma oranı & Referans \\
\hline Aspartam, fruktoz ve polidekstroz & $\% 100$ & Pong et al., 1991 \\
\hline Aspartam, ksilitol, sorbitol, fruktoz & $\% 100$ & Bakr, 1997 \\
\hline $\begin{array}{c}\text { Aspartam, sorbitol, buğday ruşeymi, } \\
\text { buğday nişastası }\end{array}$ & $\% 100$ & Baeva et al., 2000 \\
\hline Polidekstroz & $\% 25, \% 50, \% 75, \% 100$ & Hicsasmaz et al., 2003 \\
\hline Eritritol & $\% 25, \% 50, \% 75, \% 100$ & Lin et al., 2003 \\
\hline Sukraloz, maltodekstrin, ksantan gam & $\% 100$ & Khouryieh et al., 2005 \\
\hline $\begin{array}{l}\text { Sukraloz, sindirilemeyen dekstrin } \\
\text { (Fibersol-2) }\end{array}$ & $\% 20, \% 40, \% 50$ & Lin and Lee, 2005 \\
\hline $\begin{array}{l}\text { Maltitol, mannitol, ksilitol, sorbitol, } \\
\text { izomaltoz, oligofruktoz, polidekstroz }\end{array}$ & $\% 100$ & Ronda et al., 2005 \\
\hline $\begin{array}{l}\text { İzomalt, mannitol, maltitol, sukraloz, } \\
\text { ksilitol, stevia }\end{array}$ & $\% 25, \% 33, \% 50, \% 100$ & Edelstein et al., 2007 \\
\hline Polidekstroz & $\% 20, \% 40, \% 60, \% 80, \% 100$ & Kocer et al., 2007 \\
\hline Eritritol, sukraloz & $\% 25, \% 50, \% 75, \% 100$ & Akesowan, 2009 \\
\hline $\begin{array}{l}\text { Steviosit, sorbitol ile hidrokolloid (gam } \\
\text { arabik, ksantan, guar gam, karragenan, } \\
\text { karboksimetilselüloz), emülgatör } \\
\text { (glserol monostearat, sodium stearil 2- } \\
\text { laktat, polisorbat-60) }\end{array}$ & $\% 25, \% 50, \% 75, \% 100$ & Manisha et al., 2012 \\
\hline Sukraloz, polidekstroz & $\% 25, \% 50, \% 75, \% 100$ & $\begin{array}{l}\text { Martínez-Cervera et al., } \\
\text { 2012a }\end{array}$ \\
\hline Eritritol, ksantan gam & $\% 25, \% 50, \% 75, \% 100$ & $\begin{array}{l}\text { Martínez-Cervera et al., } \\
\text { 2012b }\end{array}$ \\
\hline $\begin{array}{l}\text { Mannitol, maltitol, sorbitol, laktitol, } \\
\text { fruktoz, oligofruktoz, polidekstroz }\end{array}$ & $\% 100$ & $\begin{array}{l}\text { Psimouli and Oreopoulou, } \\
2012\end{array}$ \\
\hline Polidekstroz, rebaudiosit A & $\% 20, \% 40, \% 60, \% 80, \% 100$ & Schirmer et al., 2012 \\
\hline $\begin{array}{l}\text { Rebaudiosit A, armut lifi, yulaf lifi, } \\
\text { buğday lifi, buğday kepeği, elma lifi, } \\
\text { selüloz, maltodekstrin, polidekstroz, } \\
\text { inülin }\end{array}$ & $\% 30$ & Zahn et al., 2012 \\
\hline Sorbitol, maltitol, izomalt ve eritritol & $\% 100$ & $\begin{array}{l}\text { Martínez-Cervera et al., } \\
2014\end{array}$ \\
\hline İnülin & $\% 20, \% 30, \% 40, \% 50$ & $\begin{array}{l}\text { Rodríguez-García et al., } \\
\qquad 2014\end{array}$ \\
\hline $\begin{array}{l}\text { Rebaudiosit A, eritritol karışımı } \\
\text { (stevianna) ve inülin }\end{array}$ & $\% 50, \% 100$ & Gao et al., 2016 \\
\hline Stevianna & $\% 50, \% 100$ & Gao et al., 2017 \\
\hline Stevia ekstrakt 1 & $\% 25, \% 50, \% 75$ & Palamutoğlu et al., 2018 \\
\hline Sukraloz, frenk üzümü ve aronya posas1 & $\% 30$ & Quiles et al., 2018 \\
\hline
\end{tabular}


Ksilitol birçok meyve ve sebzede doğal olarak bulunur ve ticari olarak ksilandan üretilir (Zacharis, 2012). Ksilitolun sağladığ tatlılık, suda çözünürlüğü sakkarozla benzerdir ve enerjisi $2.4 \mathrm{kcal} / \mathrm{g}$ olup enerjisi sakkarozdan daha düşüktür (King et al., 2005). Su aktivitesini azaltması sebebiyle jelatinizasyon sıcaklığını artırmaktadır (Torres et al., 2013).

Laktitol; sorbitol ve galaktozdan sentezlenen sentetik disakkarittir. Sakkarozun \%30-40 tatlılı̆̆ına sahip olup, sağladığı tatlılık profili sakkaroza benzerdir, suda iyi çözünmektedir (Newsome, 1993; Evrendilek, 2012).

Maltitol doğal olarak bulunmayıp, maltozun hidrojenasyonuyla üretilmektedir. Sakkarozun tatlılığının \%90'ına sahiptir (Bornet, 1994; Zumbé et al., 2001). Maltitolun higroskopisi, çözünürlüğü ve erime noktası sakkarozla benzer teknolojik özelliktedir (Gomez, 2008; Jamieson, 2012).

Sorbitol endüstriyel olarak nişasta ve invert şekerlerden elde edilen glikozun hidrojenezasyonuyla üretilmektedir. Sakkarozun tatlılığının \%60'ına sahip (Bournet, 1994, Zumbé et al., 2001) olan sorbitol suda çözünür ve higroskobik olması sebebiyle gıdalarda nem tutucu olarak kullanılmaktadır (Jamieson, 2012).

Ronda et al. (2005), keklerde ksilitol ve maltitol ile yapılan şeker ikamesinin sakkaroz içeren kontrol kekiyle benzer özellikte olduğunu ve duyusal değerlendirmede en yüksek kabule sahip olduğunu belirlemiştir. Ancak mannitol ile üretilen keklerin kontrol kekine göre daha düşük kalitede olduğu tespit edilmiştir. Edelstein et al., (2007) keklerde sakkaroz yerine $\% 25, \% 33, \% 50$ ve \%100 oranda izomalt, mannitol, maltitol, sukraloz, ksilitol ve stevia kullanıldığında keklerin görünüş, doku, yumuşaklık ve lezzet özellikleri açısından \%50 sakkaroz, \%50 maltitol kullanılan keklerin kontrol kekine en yakın olduğunu belirlemiştir. Martínez-Cervera et al. (2012b), keklerde sakkarozu \%25, \%50, \%75, \%100 oranında eritritol ve ksantan gam ile ikame ettiği çalışmada eritritol tek başına kullanıldığında sakkarozun fonksiyonlarını kısmi olarak sağladığını ancak hacim artışı ve dokusal özelliklerin sakkaroz kadar olmadığını saptamıştır. Eritritol ile ksantan gam birlikte kullanıldığında kekin sertliğinde azalma, yüksekliğinde, hacminde ve hava kabarcı̆̆ı sayısında artış belirlenmiştir.

Sakkaroz yerine mannitol, maltitol, sorbitol, laktitol, fruktoz, oligofruktoz ve polidekstroz kullanılan keklerde kek hamuru reolojisinin sakkaroz kullanılan keklerle benzer olması ve nişastanın jelatinizasyon sıcaklığını artırması sebebiyle en iyi sonuçların oligofruktoz, laktitol ve maltitol kullanılan keklerde elde edildiği ifade edilmiştir. Fruktoz ve mannitol kullanılan keklerin enstrümental ve duyusal ölçümlerle belirlenen kalite karakteristiklerinin ise en düşük seviyede olduğu saptanmıştır (Psimouli and Oreopoulou, 2012). Keklerde sorbitol, maltitol, isomalt ve eritritol gibi şeker alkolerinin nişasta jelatinizasyon sıcaklığını artırdığı, ancak eritritolün en az etkili olduğu belirlenmiştir. Kek hamurunun reolojik özellikleri değerlendirildiğinde ise kullanılan diğer şeker alkollerine kıyasla eritritol kullanılan kek hamurunun sakkaroz kullanılan kek hamuruna göre en farklı olduğu tespit edilmiştir. Sakkaroz kullanılan kekin yüksekliğinin bütün şeker alkolü kullanılan keklerden daha yüksek olduğu saptanmıştır. Kek sertliğinin sakkaroz kullanılan keke göre eritritol kullanıldığında arttığı, sorbitol ve maltitol kullanıldığında azaldığı, izomalt kullanıldığında ise benzer özellik gösterdiği belirlenmiştir. Duyusal olarak ise sakkaroz, sorbitol ve maltitol kullanılan keklerin kabulünde fark saptanmamıştır (MartínezCervera et al., 2014).

\subsection{Dŏ̆al Tatlandırıcılar}

Steviosit ve rebaudiosit A Stevia rebaudiana Bertoni L.'den elde edilen steviol glikozitleridir. Ekstrakte edilen bu bileşikler sakkarozdan 300 kat daha tatlıdır. Ayrıca sıcaklığa dayanıklılıkları fazla olması sebebiyle steviol glikozitleri kek gibi fırın ürünlerinde kullanılabilecek uygun doğal tatlandırıcılardır (Carakostas et al., 2012). Steviol glikozitleri düşük kalori değerine (2.7 kcal/g) sahip olup kariyojenik olmayan özellik göstermektedir (Lemus-Mondaca et al., 2012). Steviol glikozitlerinin tatlandırıcı olarak keklerde kullanıldığ (Schirmer et al., 2012), inülin (Gao et al., 2016) ve lif kaynakları (Zahn et al., 2012) ile beraber kullanıldığı saptanmıştır.

Keklerde sakkaroz ikamesi olarak steviosit ve sıv1 sorbitol kullanımının (\%25, \%50, \%75 ve \%100) hidrokolloid (gam arabik, ksantan, guar gam, karragenan, karboksimetilselüloz), emülgatör (gliserol monostearat, sodium stearil 2-laktat, polisorbat-60) ve acılığı giderilmiş çemen tohumuyla birlikte kekin reolojik, mikroyapı ve kalite özellikleri üzerine etkisinin araştırıldığı bir çalışmada kek hamurunda hava kabarcığı dağılımının \%100 sıv1 sorbitol, ksantan ve polisorbat-60 birlikte kullanıldığında kontrol kekiyle benzer özellikte olduğu saptanmıştır. Sıvı sorbitolün kullanıldığ1 ürünler şekerin kullanıldığ1 ürünlere göre daha düşük viskozitedir. Hidrokolloid ve emülgatör kullanımı kek hamurunun viskozitesini 
artırmakta, sertliği azaltmakta, iç yapışkanlığı artırmaktadır. Duyusal olarak kabul edilebilir yapıda olan kekin sıvı sorbitol, ksantan, polisorbat-60 ve acıllı̆ı giderilmiş çemen tohumuyla beraber kullanıldığı ürünlerde sağlandığı tespit edilmiştir (Manisha et al., 2012).

Schirmer et al. (2012), keklerde sakkarozu $\% 20, \% 40, \% 60, \% 80$ ve $\% 100$ oranında rebaudiosit A ve polidekstroz ile ikame ettikleri çalışmalarında polidekstroz kullanılan kek hamurlarının kayma gerilimine daha duyarlı olduğunu belirlemiştir. Şeker yerine $\% 100$ polidekstroz kullanılan kek hamurunun sertliğinin şeker içeren ürünlere göre polidekstrozun yüksek molekül ağırlı̆̆ı ve su absorblaması nedeniyle \%13 daha sert olduğu tespit edilmiştir. Ancak pişmiş kekler değerlendirildiğinde polidekstroz içeren keklerin sakkaroz içeren keklerle benzer yumuşak yapı ve yüksek hacim özelliği gösterdiği tespit edilmiştir. Benzer olarak, keklerde rebaudiosit A'nın şekeri \%30 azaltmak amacıyla armut lifi, yulaf lifi, buğday lifi, buğday kepeği, elma lifi, selüloz, maltodekstrin, polidekstroz ve inülin ile birlikte kullanıldığı bir çalışmada rebaudiosit A'nın inülin ve polidekstrozla beraber kullanıldığı keklerin kontrol kekine en yakın özellik gösterdiği belirlenmiştir. Buğday kepeği ve elma lifinin şeker ikamesi olarak kullanımı kek renginde değişikliğe ve istenmeyen lezzet oluşumuna sebep olduğu, yulaf, armut ve buğday kepeği kullanımı ile dağılabilirliğin artı̆̆ı, elastisitenin azaldığı saptanmıştır (Zahn et al., 2012). Şeker azaltmanın \%50 seviyesinde stevianna (rebaudiosit A ve eritritol karışımı) veya inülin ile yapıldığı keklerde glisemik cevabın düzenlenebildiği ve dokusal özelliklerin etkilenmediği belirlenmiştir (Gao et al., 2016). Sakkarozun \%50 oranında stevianna ile ikame edildiği ürünlerin duyusal analizler sonucunda genel kabul değerinin yüksek olduğu belirlenmiştir. Sakkaroz yerine \%100 stevianna içeren keklerin kontrol örneğine göre daha sert ve sıkışı yapıda olduğu tespit edilmiştir. Duyusal analiz sonuçlarına göre de \%100 stevianna içeren keklerin kabulünün düşük, sert yapıda ve kuru ağız hissi yarattığ1 belirlenmiştir (Gao et al., 2017).

Düşük kalori kek üretmek amacıyla kekteki sakkarozun $\% 25, \% 50$ ve $\% 75$ 'i oranında stevia ekstraktı ile yer değiştirildiği çalışmada duyusal değerlendirme sonucunda sakkarozun \%25 oranında stevia ile ikame edildiği keklerin genel kabulünün en fazla olduğu belirlenmiştir. Kekin kalite özellikleri göz önüne alındığında ise sakkarozun yerine $\% 50$ oranında stevia kullanılan keklerin ön plana çıktığı belirlenmiştir. Aynı zamanda kalori değerinin de kontrol grubuyla kıyaslanınca \%11 azaltıldığı tespit edilmiştir (Palamutoğlu et al., 2018).

\subsection{Yapay Tatlandiricular}

Yapay tatlandırıcılar sentetik organik bileşikler olup, tatılıkları sakkarozdan çok yüksektir. Kekte şeker azaltma çalışmalarında yapay tatlandırıcı olarak aspartam ve sukralozun kullanıldığı saptanmıştır (Pong et al., 1991; Bakr, 1997; Baeva et al., 2000; Khouryieh et al., 2005; Lin and Lee, 2005; Edelstein et al., 2007; Akesowan, 2009; Martínez-Cervera et al., 2012a; Quiles et al., 2018). Aspartam sakkarozdan 180220 kat daha tatlı olmakla birlikte $150^{\circ} \mathrm{C}$ üzerindeki sıcaklıklarda yapısı bozulmaktadır (Attia et al., 1993). Sukraloz, sakkarozdan 600 kat daha tatlı olup, benzer tatlılık profili sergilemekte ve ağızda acı tat bırakmamaktadır. Sıcaklık ve aside dayanıklılı̆ı sayesinde pişirmeyle yapısı bozulmamakta, tatılı̆ğını korumaktadır (Duyff, 2002). Sakkaroz yerine yapay tatlandırıcı kullanılan keklerde, yapay tatlandırıcılar sakkarozun kekte meydana getirdiği yapısal özellikleri sağlayamadığı için genellikle şeker alkolleri, polidekstroz ve diyet lifi kaynakları gibi hacim vericilerle birlikte kullanılmaktadır.

Pong et al. (1991), keklerde sakkaroz ikamesi olarak aspartam, fruktoz ve polidekstroz kullanıldığında sakkaroz içermeyen kek hamurunun daha yüksek $\mathrm{pH}$ değerine ve spesifik yoğunluğa sahip olduğu saptamıştır. Kekin ise kontrol örneğine göre yüksekliğinin daha düşük, dokusunun daha sert, nem içeriğinin daha fazla renginin daha açık olduğu tespit edilmiștir. Keklerde sakkaroz yerine aspartam ve ksilitol (0.25:99.75), aspartam ve sorbitol (0.25:99.75), aspartam ve fruktoz (0.25:99.75), sorbitol, ksilitol ve aspartam (39.875:59.875:0.250), ksilitol, fruktoz ve aspartam (39.875:59.875:0.250), sorbitol, fruktoz ve aspartam (39.875:59.875:0.250) karışımları kullanıldığında duyusal değerlendirme sonucunda

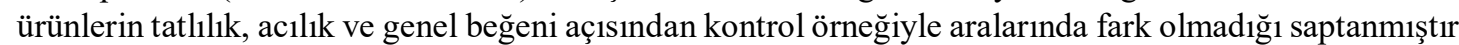
(Bakr, 1997). Baeva et al. (2000) sakkaroz yerine aspartam ile sorbitol, buğday ruşeymi ve buğday nişastası kullanarak ürettikleri diyabetik keklerden buğday rușeymi içeren keklerin kontrol örneğine fiziksel ve duyusal açıdan en yakın örnek olduğunu belirlemiştir. Sakkaroz içermeyen keklerin enerji değerinin \%25 azaldığı ve buğday ruşeymi içeren sakkarozsuz keklerin ise \%29 oranında enerjisinin azaldığı tespit edilmiştir.

Maltodekstrin ve ksantan gamın sukraloz ile beraber kullanıldığ sakkaroz içermeyen keklerin kontrol kekine göre nem içeriğinin daha yüksek, pişirme kaybının düşük ve hacminin daha az olduğu belirlenmiştir. Sakkaroz yerine keklerde maltodekstrin kullanımı nem kaybını azaltmaktadır. Ksantan

30 | P a g e 
gamın ise su aktivitesine etkisi olmayıp, pişirme sırasında nem kaybını azaltmaktadır. Duyusal olarak da sakkaroz içermeyen keklerin kontrol kekinden daha fazla beğenildiği ancak kontrol kekinin çiğnenebilirliğinin şekersiz keke göre daha iyi olduğu saptanmıştır (Khouryieh et al., 2005).

Sakkarozun $\% 20, \% 40$ ve $\% 50$ oranında sindirilemeyen dekstrin (Fibersol-2) ve sukralozla ikame edildiği ürünlerde duyusal özellikler açısından farklılık belirlenmemiştir. Sukraloz ve Fibersol-2'nin sakkaroz yerine kullanımı $\% 60$ ve $\% 80$ seviyesine çıktığında kekin parlaklığında ve sarılığında artış saptanmıştır. Ancak keklerin nemlilik ve tatlılıkları arasında fark belirlenmemiştir. Hedonik testte ise genel beğeni açısından sakkaroz içeren kontrol keki ile sakkaroz ikame oranı $\% 20, \% 40$ ve $\% 50$ olan kekler arasında fark saptanmamıştır (Lin and Lee, 2005).

Az yağlı keklerde sakkaroz $\% 25, \% 50, \% 75$ ve $\% 100$ oranında sukraloz ve eritritol ile ikame edildiğinde sukraloz ve eritritolün kullanım oranı arttıkça spesifik hacmin azaldığı, ancak ağırlık kaybı ve su aktivitesinin artığı saptanmıştır. Yüksek oranda şeker ikamesi kullanılan ürünler sakkaroz içeren kekle kıyaslandığında kekin daha koyu renkli, daha nemli, daha sert ve az tatlı olduğu belirlenmiştir. Sakkaroz ikamesi oranı $\% 50$ olan keklerin duyusal olarak kabul edilebilir olduğu ve $\% 21.3$ oranında kalori azalmasının sağlandığı tespit edilmiştir (Akesowan, 2009).

Keklerde sakkaroz yerine $\% 25, \% 50, \% 75$ ve $\% 100$ oranında kullanılan sukraloz:polidekstroz karışımının (1:1012) kullanıldığında kek yüksekliği, sertlik, esneklik, iç yapışkanlık, çiğnenebilirlik, direnç ve hücre sayısında azalma olduğu belirlenmiştir. Sakkarozun \%50'si oranında sukraloz ve polidesktroz karışımı kullanılan keklerin ise görünüş, renk, doku, lezzet, tatlılık ve genel kabulünün kontrol örneğiyle benzer olduğu belirlenmiştir (Martínez-Cervera et al., 2012a)

Meyve posaları kullanılarak keklerde sakkarozun \%30 azaltılması sağlanan bir çalışmada keklerde yüksek lif ve biyoaktif bileşik açısından zengin frenk üzümü ve aronya posası ile sukraloz kullanılmıştır. Sakkaroz içeriği azaltılmış keklerin sertliğinde artış ve daha fazla sayıda küçük hücre oluşumu belirlenmiştir. Meyve posası kullanılarak sakkarozu azaltılan keklerin duyusal olarak tüketici tarafindan da kabulünün yüksek olduğu tespit edilmiştir (Quiles et al., 2018).

\section{Sonuç}

Keklerdeki şekeri azaltmak amacıyla sakkaroz ikamesi kullanılan keklerde sadece tek tip tatlandırıcı kullanılarak sakkarozun fonksiyonlarını sağlamak mümkün değildir. Doğal ve yapay tatlandırıcılar kullanılan keklerin, sakkaroz kullanılan keklerle benzer tatllıkta olduğu ancak ürünün mikroyapısında negatif etkilerinin olduğu saptanmıştır. Tatlandırıcılar hacim vericilerle birlikte kullanıldığında ise ürünün dokusal özelliklerinde iyileşme sağlanmıştır. Şeker alkollerinin keklerde sağladığı hacim özellikleri sakkaroz kullanılan keklerle benzer özellikte olup, tatlılıklarının az olması sebebiyle kabul edilebilirliklerinin düşük olduğu saptanmıştır. Genel olarak şeker içeriği düşük kekin renk, lezzet ve doku özelliklerinin iyileştirilmesi için tatlandırıııların genellikle karışım halinde ve hacim vericilerle beraber kullanılması gerektiği belirlenmiştir.

\section{Kaynaklar}

Akesowan, A. (2009). Quality of reduced-fat chiffon cakes prepared with erythritol-sucralose as replacement for sugar. Pakistan Journal of Nutrition, 8(9), 1383-1386.

Attia, E. S. A., Shehata, H. A., \& Askar, A. (1993). An alternative formula for the sweetening of reduced-calorie cakes. Food Chemistry, 48(2), 169-172.

Baeva, M. R., Panchev, I. N., \& Terzieva, V. V. (2000). Comparative study of texture of normal and energy reduced sponge cakes. Food/Nahrung, 44(4), 242-246.

Bailey, R. et al. (2018). Sources of added sugars in young children, adolescents, and adults with low and high intakes of added sugars. Nutrients, 10(1), 102.

Bakr, A. A. (1997). Application potential for some sugar substitutes in some low energy and diabetic foods. Food/Nahrung, 41(3), 170-175.

Beesley, P. M. (1995). Sugar functionality reviewed. Food Technology International Europe, 1, 8789. 
Bornet, F. R. (1994). Undigestible sugars in food products. The American Journal of Clinical Nutrition, 59(3), 763S-769S.

Carakostas, M. et al. (2012). Steviol glycosides. In L.O. Nabors (Eds.), Alternative Sweeteners (p. 159-176). Boca Raton: CRC Press.

Davis, E. A. (1995). Functionality of sugars: physicochemical interactions in foods. The American Journal of Clinical Nutrition, 62(1), 170S-177S.

de Cock, P. (2012). Erythritol. In L.O. Nabors (Eds.), Alternative sweeteners (p. 249-264). Boca Raton: CRC Press.

de Leenheer, L. (1996). Production and use of inulin: industrial reality with a promising future. In $\mathrm{H}$. van Bekkum, H. R€oper, A.G.J. Voragen. (Eds.), Carbohydrates as organic raw materials (p. 6792). III. Weinheim: VCH.

Deis, R.C., \& Kearsley, M.W. (2012). Sorbitol and mannitol. In K. O’Donnell, M.W. Kearsley (Eds.), Sweeteners and sugar alternatives in food technology (p. 331-346). Chichester: Wiley- Blackwell.

Duyff, R. (2002). American dietetic association complete food and nutrition guide. 2 nd ed. (p. 125 128). Hoboken, New Jersey: Wiley \& Sons.

Edelstein, S. et al. (2007). Comparisons of six new artificial sweetener gradation ratios with sucrose in conventional-method cupcakes resulting in best percentage substitution ratios. Journal of Culinary Science \& Technology, 5(4), 61-74.

Evrendilek, G.A. (2012). Sugar alcohols (polyols). In T. Varzakas, A. Labropoulos, S. Anestis (Eds.), Sweeteners: nutritional aspects, applications, and production technology p. 45-78. Boca Raton: CRC Press.

Gao, J. et al. (2017). Effects of sugar substitution with "stevianna" on the sensory characteristics of muffins. Journal of Food Quality, 2017.

Gao, J. et al. (2016). Effect of sugar replacement with stevianna and inulin on the texture and predictive glycaemic response of muffins. International Journal of Food Science \& Technology, 51(9), 1979-1987.

Gomez, M. (2008). Low-sugar and low-fat sweet goods. In S.G. Sumnu, S. Sahin (Eds.), Food engineering aspects of baking sweet goods (p.245-273). Boca Raton: CRC Pres.

Goossens, J. \& Roper, H. (1994). Erythritol: a new sweetener. Food Science and Technology Today (United Kingdom).

Hempel, S., Jacob, A. \& Rohm, H. (2007). Influence of inulin modification and flour type on the sensory quality of prebiotic wafer crackers. European Food Research and Technology, 224(3), 335-341.

Hicsasmaz, Z. et al. (2003). Effect of polydextrose-substitution on the cell structure of the high-ratio cake system. LWT-Food Science and Technology, 36(4), 441-450.

Jamieson, P.R. (2012). Sorbitol and mannitol. In L.O. Nabors (Eds.), Alternative Sweeteners (p. 333 348). Boca Raton: CRC Press.

Khouryieh, H. A. et al. (2005). Physical and sensory characteristics of no-sugar-added/low-fat muffin. Journal of Food Quality, 28(5-6), 439-451. 
Kim, S. S. \& Setser, C. S. (1992). Wheat starch gelatinization in the presence of polydextrose or hydrolyzed barley beta-glucan. Cereal Chemistry, 69(4), 447-451.

King, N. A. et al. (2005). Evaluation of the independent and combined effects of xylitol and polydextrose consumed as a snack on hunger and energy intake over $10 \mathrm{~d}$. British Journal of Nutrition, 93(6), 911-915.

Kocer, D. et al. (2007). Bubble and pore formation of the high-ratio cake formulation with polydextrose as a sugar-and fat-replacer. Journal of Food Engineering, 78(3), 953-964.

Lemus-Mondaca, R. et al. (2012). Stevia rebaudiana Bertoni, source of a high-potency natural sweetener: A comprehensive review on the biochemical, nutritional and functional aspects. Food Chemistry, 132(3), 1121-1132.

Lin, S. D., Hwang, C. F., \& Yeh, C. H. (2003). Physical and sensory characteristics of chiffon cake prepared with erythritol as replacement for sucrose. Journal of Food Science, 68(6), 2107-2110.

Lin, S. D., \& Lee, C. C. (2005). Qualities of chiffon cake prepared with indigestible dextrin and sucralose as replacement for sucrose. Cereal Chemistry, 82(4), 405-413.

Lin, S. J. et al. (2001). Screening and production of erythritol by newly isolated osmophilic yeastlike fungi. Process Biochemistry, 36(12), 1249-1258.

Louie, J. C. Y., \& Tapsell, L. C. (2015). Association between intake of total vs added sugar on diet quality: a systematic review. Nutrition reviews, 73(12), 837-857.

Manisha, G., Soumya, C., \& Indrani, D. (2012). Studies on interaction between stevioside, liquid sorbitol, hydrocolloids and emulsifiers for replacement of sugar in cakes. Food Hydrocolloids, 29(2), 363-373.

Martínez-Cervera, S. et al. (2012). Effect of using erythritol as a sucrose replacer in making Spanish muffins incorporating xanthan gum. Food and Bioprocess Technology, 5(8), 3203-3216.

Martínez-Cervera, S., Salvador, A., \& Sanz, T. (2014). Comparison of different polyols as total sucrose replacers in muffins: Thermal, rheological, texture and acceptability properties. Food Hydrocolloids, 35, 1-8.

Martínez-Cervera, S. et al. (2012). Rheological, textural and sensorial properties of low-sucrose muffins reformulated with sucralose/polydextrose. LWT-Food Science and Technology, 45(2), $213-220$

Newsome, R. (1993). Sugar substitutes. In A.M. Altschul, M. Decker (Eds.), Low-calorie foods handbook (p. 139-170). New York: CRC Press.

Niness, K. (1999). Breakfast foods and the health benefits of inulin and oligofructose. Cereal Foods World, 44(2): 79-81.

Nip, W.K. (2006). Sweeteners. In Y.H. Hui (Eds.), Bakery products: science and technology (p. 137159). Ames: Blackwell.

Palamutoğlu, R., Kasnak, C., Moral, B. Şeker İkamesi Olarak Stevya Estraktı Kullanımının Keklerin Bazı Fiziksel ve Duyusal Özellikleri Üzerine Etkisi. Karadeniz Fen Bilimleri Dergisi, 8(1), 98108.

Paton, D., Larocque, G. M., \& Holme, J. (1981). Development of cake structure: influence of ingredients on the measurement of cohesive force during baking. Cereal Chemistry. 58, 527-529. 
Perego, P. et al. (2007). Effects of changes in ingredient composition on the rheological properties of a biscuit industry dough. International Journal of Food science \& Technology, 42(6), 649-657.

Pomeranz, Y., Meyer, D., \& Seibel, W. (1984). Wheat, wheat-rye, and rye dough and bread studied by scanning electron microscopy. Cereal Chemistry, 61, 53-59.

Pong, L. et al. (1991). Evaluation of alternative fat and sweetener systems in cupcakes. Cereal Chemistry, 68(5), 552-555.

Psimouli, V., \& Oreopoulou, V. (2012). The effect of alternative sweeteners on batter rheology and cake properties. Journal of the Science of Food and Agriculture, 92(1), 99-105.

Quiles, A. et al. (2018). Use of berry pomace to replace flour, fat or sugar in cakes. International Journal of Food Science \& Technology, 53(6), 1579-1587.

Roberfroid, M. \& Slavin, J. (2000). Nondigestible oligosaccharides. Critical Reviews in Food Science and Nutrition., 40(6), 461-480.

Rodríguez-García, J., Salvador, A., \& Hernando, I. (2014). Replacing fat and sugar with inulin in cakes: bubble size distribution, physical and sensory properties. Food and Bioprocess Technology, 7(4), 964-974.

Ronda, F. et al. (2005). Effects of polyols and nondigestible oligosaccharides on the quality of sugarfree sponge cakes. Food Chemistry, 90(4), 549-555.

Rößle, C., Ktenioudaki, A., \& Gallagher, E. (2011). Inulin and oligofructose as fat and sugar substitutes in quick breads (scones): a mixture design approach. European Food Research and Technology, 233(1), 167.

Schirmer, M. et al. (2012). Physicochemical interactions of polydextrose for sucrose replacement in pound cake. Food Research International, 48(1), 291-298.

Tetzloff, W. et al. (1996). Tolerance to subchronic, high-dose ingestion of erythritol in human volunteers. Regulatory Toxicology and Pharmacology, 24(2), S286-S295.

Torres, M. D., Raymundo, A. \& Sousa, I. (2013). Effect of sucrose, stevia and xylitol on rheological properties of gels from blends of chestnut and rice flours. Carbohydrate Polymers, 98(1), 249256.

Varzakas, T., \& Ozer, B. (2012). Application of sweeteners in food and drinks. In T. Varzakas, A. Labropoulos, S. Anestis (Eds.), Sweeteners: nutritional aspects, applications, and production technology (p. 209-254). Boca Raton: CRC Press.

Wilderjans, E. et al. (2013). Ingredient functionality in batter type cake making. Trends in Food Science \& Technology, 30(1), 6-15.

Zacharis, C. (2012). Xylitol. In K. O'Donnell, M.W. Kearsley (Eds) Sweeteners and sugar alternatives in food technology (p. 331-346). Chichester: Wiley- Blackwell.

Zahn, S. et al. (2013). Combined use of rebaudioside A and fibres for partial sucrose replacement in muffins. LWT-Food Science and Technology, 50(2), 695-701.

Zumbe, A., Lee, A. \& Storey, D. (2001). Polyols in confectionery: the route to sugar-free, reduced sugar and reduced calorie confectionery. British Journal of Nutrition, 85(S1), S31-S45. 